\title{
The Struggles of Reluctant Workplace Bloggers
}

\author{
Latisha Asmaak Shafie \\ Academy of Language Studies, Universiti Teknologi MARA Perlis \\ Arau 02600, Perlis, M Malaysia \\ Tel: 60-16-531-8095 E-mail: ciklatisha@perlis.uitm.edu.my \\ Kamaruzaman Jusoff (Corresponding author) \\ Faculty of Forestry \\ Universiti Putra Malaysia, 43400 Serdang, Selangor, Malaysia
}

\begin{abstract}
Blogs act as knowledge repositories and personalize knowledge management within learning organizations. These knowledge repositories allow capturing and disseminating tacit knowledge which improve task implementations. However, workplace blogging is not popular among academicians as there are not many academicians blog about their working experiences. Thus, this study investigates the causes of workplace blogging resistance among four language lecturers at a local university in Malaysia. Interviews were conducted to identify the arguments over the resistance of workplace blogging. The findings of the study suggest several suggestions to overcome the resistance of workplace blogging.
\end{abstract}

Keywords: Knowledge workers, Tacit knowledge, Workplace blogging, Knowledge conversion, Language lecturers, Reluctant workplace bloggers

\section{Introduction}

Learning organizations are organizations where people continuously improve their capabilities to achieve organizational aims through collective thinking, aspirations and collective learning (Senge, 1990). A blog ; an online journal contains dated entries in reverse chronologically arranged about topics of the author's choice, provides opportunities for reflection and analysis through feedback. These opportunities allow the writers and the readers to understand knowledge and construct new knowledge as blogs capture and disseminate tacit knowledge which encourage workplace learning. External workplace blogs are public relations tools as they discuss new products or the opinions of spokespersons for the organizations. Internal workplace blogs are communal and allow workers share views regardless of the hierarchy.

Most learning at work is non-formal as learning is clearly not specified or planned in advance and influenced by (Nonaka,1994).Organizational knowledge is categorized into three types of knowledge; tacit knowledge, explicit knowledge and background knowledge $($ Choo, 1998). The knowledge conversion between explicit knowledge and tacit knowledge converts either tacit knowledge to explicit knowledge or explicit knowledge to tacit knowledge (Nonaka et al, 2000). Learning organizations comprise of communities of practices which act as living repositories of their members' knowledge. A community of practice is a social structure which shares a shared identification, learning process through communal activities and its practice in form of communal routines, stories and lessons learned (Lave and Wenger, 1996). Competent practitioners rely on a tacit knowing-in-action to help them act within circumstances (Polanyi,1966).

In teaching profession, experienced teachers develop rich and well-organized knowledge bases which enable them to draw readily on their past experiences (Calderhead, 1996). Experienced teachers are expert in subject matter, pedagogy and didactics ( Broome,1991, Beijaard,Verloop and Vermont,2000). The expertise in the domains are influenced by teaching context, teaching experiences and the biography of the teachers.Darwin (2000) propogates mentoring as a strategy to share intellectual and emotional resources where individuals are encouraged to share both tacit and explicit knowledge with others. In training novices to become experts, Darwin (2000) states those critical reflections mentoring is considered as one of the strategies to share intellectual and emotional resources. Individuals are encouraged to share both tacit and explicit knowledge with others in mentoring relationships.

Stories in learning organizations enable workers understand the works of an organization. Through stories, tacit knowledge is being converted as it provides richer engaging interaction that connect listeners and storytellers (Weinberger, 2001).Blogs share salient features of storytelling and are more accessible as they reach wider audience ( Nichani and Rajamanichan, 2001). Dwyer (2007) explains that blogging is a collaborative activity that lets colleagues and competitors to the blogger's internal thinking which requires openness in order to unlock the benefits of blogging. The objective of this study was to identify the arguments of the reluctance of workplace blogging among four language lecturers at a university in Malaysia. 


\section{Methodology}

The research was a case study of four language lecturers at a local university. They were experienced lecturers teaching English to diploma and degree undergraduates in multiple disciplines for more than 10 years. Their highest level of education was at master's level. All of them were competent computer and internet users in their professional and personal lives.

A blog was created for all the participants who were members of a collaborative research team at the university to enable these participants to share their experiences. The participants were informed about the aims of the blog and they were asked to write about their teaching experiences. The participants were given freedom to write the topics for their entries in the blog. They were given the address of the blog, the user identity and the password for the blog. Nevertheless, these participants were not given any training on posting blog entries. The participants were given a month to contribute to the blog. However the participants did not write any blog entries. The action propelled the researcher to investigate the arguments of the participants for not participating in the workplace blogging.

The interview session was conducted a month after the blog creation. English was used during the interview session. The interviews were conducted to determine the arguments for the resistance of workplace blogging. Several themes and phenomena that emerged from the data were scrutinized to enable more understanding of the resistance of using workplace blogging for capturing and disseminating effective documentations of tacit knowledge using workplace blogs.

\section{Results and Discussion}

\subsection{Time constraint}

All four participants agreed that time constraint influenced their decisions not to contribute to any entries in the blog. All the participants allocated their time on daily demands such as family demands, students' demands, teaching load, researches and writing journal articles. The participants had to teach sixteen to twenty hours per week. Another reason contributing to time constraint was poor internet connection. The participants believed that they sacrificed their valuable time if they wrote entries in the blog as these participants needed a long time to construct ideas, edit the content, the grammar and reply comments. The participants were language lecturers. Thus, it is natural for language practitioners to be conscious about the language as they believed that they needed to be perfect in their writing when they wrote the blog entries.

\subsection{Unfamiliarity}

All the participants were familiar with the internet as they had to use the internet for internal and external communications such as internal and external email services to communicate for work and personal purposes. Internet was heavily used for research purposes. The participants depended on online journal and online articles for research purposes. Another usage of the internet among the participants was online dictionary.However, they were unfamiliar with blog navigation. Three of the participants confessed that the last time they posted blog entries was five years ago. Furthermore, a participant has never posted a blog entry in her life. She was a novice in blog navigation. Thus, the participants confessed that they needed to learn more about writing and posting blog entries. Nevertheless, all the participants were reluctant to learn more about workplace blogging as the participants were not willing to allocate time for the blog training and workplace blogging.

\subsection{Preference for face- to- face informal discussion}

All the participants preferred face-to-face interaction such as informal discussions during breakfast or lunch at the cafeteria and at their own offices. The participants concluded that these informal discussions were more intimate, friendlier, less threatening and more conducive for sharing session. Thus these participants allocated time for informal discussions by having lunch, attending social gatherings and chatting at colleagues' offices. The participants conceived by attending these face-to-face informal discussions, they invested in quality time with their colleagues as well as one of effective ways to reduce their stress. The participants were able to socialize with colleagues and at the same time were able to exchange working experiences and best practices. Interaction through workplace blogs was deemed to be impersonal and threatening. Thus, the participants did not prefer interaction through workplace blogging.

\subsection{Willingness to share the knowledge}

All the participants were not interested in sharing their knowledge with the public as they felt that teaching was a private domain. They believed that other lecturers at their institution and other higher institutions knew the best teaching practice for their classes. Thus, the participants believed that their knowledge were not able to help other practitioners even though they believed in their best practices.However three of the participants determined that their knowledge only be shared with preferred colleagues at their own institute. The position taken might be influenced by their beliefs that their colleagues had helped these participants in the past and they were expected to return the favours. Nevertheless one of the participants was unwilling to share her knowledge with others. The participant adamantly 
believed that her knowledge could only benefit herself as the efforts to get the knowledge were her own. Thus, it was only fair to be the sole beneficiary for her knowledge.

\subsection{Risks}

All the participants were concerned about the errors of the content and the language of the as the blog entries were available to the public. The contents and the language were available to be scrutinized by the public. The participants were apprehended of being misjudged by the public as the public might have negative impressions of the participants. In addition, the participants were concerned about the liability risks as the posts in the blog served as the evidence of their writings. The participants were concerned that their entries in the blog jeopardized their careers or they might be sued by the public or the institution. For example, a former Delta Air Lines stewardess was allegedly being fired after she posted her photos in uniform (Baldas, 2008). Furthermore, the participants were unsure other language lecturers appreciated their best practices as others did not ask about the participants' practices.

\subsection{Lack of interest}

The participants admitted that it was due to their lack of interest in blogging that they did not post any entry in the blog. They were not interested in the blogging activity itself. The participants contributed their lack of interest in workplace blogging was caused by their belief that workplace blogging was insignificant when compared to their teaching loads and researches.

The poor internet connection influenced the participants' decision to blog. The participants were convinced that the poor internet connection deterred them from spending less time when writing entries in the blog. Therefore, the participants decided not to blog as blogging prevented them from their demanding demands.

\subsection{Health issues}

The participants attributed the health issues as one of the reasons they did not blog at work. One participant suffered from severe back pain and eye strain when she worked continuously in front of the computer for a long time. Other participants admitted that dealing with the unfamiliar experience such as writing the blog increased their stress level and jeopardized their health.

\section{Conclusions}

Farmer and Bartlett-Bragg (2005) predict the new bloggers face several difficulties during initial phase of blogging. These difficulties lie in learning software formats, feelings of uncertainty in writing publicly and lack of motivation during blogging sessions. These difficulties were apparent among the four language lecturers. Other emerging issues that contribute to this workplace blogging resistance were time constraint, willingness to share knowledge with others, preference for face-to-face informal discussions and health issues. These emerging issues influenced these four language lecturers not to participate in the workplace blogging.

Based on the findings of the study, the following recommendations are suggested to academicians and administrators of higher institutions so knowledge can be shared and new knowledge can be constructed. Blogs offer opportunities to the lecturers as the blogs are more personalized, accessible and flexible. Academicians rely other academicians' expertise to comprehend knowledge .The present method of capturing and disseminating knowledge depends on socialization through face-to-face interaction. Since academicians do not have much time for face- to- face interaction, they need of a more accessible medium of communication which can be archived for future references or for others usage. This need demands new tools of capturing and disseminating tacit knowledge. In addition to that, administrators should realize in the long run it is beneficial to have workplace blogs as these blogs act as knowledge repositories. This is beneficial whenever any faculty members leave the institutions, their tacit knowledge could still be retained and accessed by other faculty members. It could act as an informal training tool for the new faculty members.

Academicians should be trained to be more competent in knowledge management tools which expose them to more accessible knowledge repositories. When the higher institutions as learning organizations advocate workplace blogging among academicians, the number of reluctant workplace bloggers among academicians is decreased .This is because the academicians aware of the importance of the practice at their institutions. Therefore, these academicians will be motivated and make efforts to write and contribute their knowledge to the organizations.

\section{References}

Baldas, T. (2008). Work Blogs Take Off, and So Do the Suits. The National LawJournal. [Online] Available: http:// http://www.law.com/jsp/legaltechnology/pubArticleLT.jsp?id=1202424595821.

Beijaard, D., Verloop, N. \& Vermont, J. D. (2000).Teachers' perception of professional identity: An exploratory study from a personal knowledge perspective.Teacher Teaching \& Teacher Education,16,749-764.

Boje, D. M. (1991).The storytelling organization: A study of story performance in an office supply firm .Administrative Science Quarterly,36(1),106-126. 
Broome, R. (1991).Types of knowledge and professional self-concept. Zeitschruff fer pedagogic,37,769-785.

Bruner, J. S. (1996).The culture of education. Cambridge, MA :Harvard University Press.

Calderhead, J. (1996).Teachers:Beliefs and knowledge.In C.Berliner,R.C.Calfee(Eds),Handbook of Educational Psychology (pp 709-725).New York:Macmillan.

Carter, K. (1990). Teacher's knowledge and learning to teach. In W.R.Houston (Ed.), Handbook of research on teacher education (pp 291-310).NY: Macmillan.

Chase, W. G. \& Simon, H. A. (1973).Perception in Chess.Cognitive Psychology,4,55-81.

Choo, C.W. (1998). The knowing organization: How organizations use information to construct meaning,create knowledge, and make decisions. New York:Oxford University Press.

Crossan, M. M., Lane, H. W. \& White, R. E. (1999). An organizational learning framework :From intuition to institution.Academy of management Review,24,522-537.

Darwin, A. (2000). Critical reflections on mentoring in work settings. Adult Education Quarterly,5,3,197-211.

De Jong, J. (1997). Research into on-the-job training: a state of the art.International Journal of Educational Research, 25,5,449-471.

Dwyer, P. (2007).Building Trust with corporate blogs. Paper presented at International Conference on Weblogs and Social Media, Boulder CO. [Online] Available: http://icwsm.org/papers/2--Dwyer.pdf (Feb 15, 2009)

Farmer, J \& Bartlett-Bragg, A (2005): Blogs @anywhere: High fidelity online communication. Proc. ASCILITE, Brisbane, Qld, Australia, 197-203.

Gherardi , S., Nicolini,D. \& Odella, F. (1988). Towards a social understanding of how people learn in organization:The notion of situated curriculum. Management Learning , 29(3),273-297.

Lave, J. \& Wenger, E. (1996). Situated Learning: Legitimateperipheral participation.Cambridge:Cambridge University Press.

Morgan, G.. (1986). Images of organization.California: Sage.

Nonaka, I. (1994). A dynamic theory of organizational knowledge creation.Organisation Science,5(1), 14-37.

Nonaka, I., Toyama, R. \& Konno, N. (2000).Seci,Ba and leadership: A unified model of dynamic knowledge creation. Long Range Planning, 33,5-34.

Nonaka, I., \& Takeuchi,H. (1995). The knowledge-creating company:How Japanese companies create the dynamics of innovation.New York:Oxford University Press.

Nichani,M. \& Rajamanichan,V. (2001). Grassroots KM through blogging. [Online] Available: http://www.elearningpost.com/articles/archives/grassroots_km_through_blogging/ (January 14, 2009).

Olson, J. R. \& Biolsi,K.J. (1991).Technique for representing expert knowledge.In Ericson,K.A. and Smith,J.(Eds).Toward a general theory of expertise. (pp 240-285). Cambridge : Cambridge University Press.

Polanyi, M. (1966).The tacit dimension.London: Routledge and Kegan Paul.

Sanchez, R., \& Mahoney, J. T. (1996).Modularity, flexibility and knowledge management in product and organization design.Strategic Management Journal, 17(10),63-67.

Senge, P. (1990). The Fifth Discipline: The art and practice of the learning organization. New York: Doubleday.

Sternberg, R. J. \& Horvarth, J. A. (1995). A prototype view of expert teaching. Educational Researcher,24(6),9-17.

Weinberger, S. (1993).Overcoming criticism and writing across the curriculum.Chronicles of Higher Education, 40, 27-54. 